\title{
The role of the approach response in secondary reinforcement ${ }^{1}$
}

\author{
NANCY A. MYERS AND MONA MORNINGSTAR
} UNIVERSITY OF MASSACHUSETTS

Kindergarten $S$ s received two light stimuli during training on a push-button task, one (positive) on candy reinforced trials, and one (negative) on all other trials. During extinction all responses yielded the positive stimulus for half the groups, the negative stimulus for the others. A door over the slot-tray was added for experimental groups, and was locked during extinction for half the Ss. For three control groups there was no door present. Least extinction responses were made by the locked door groups, and the positive stimulus groups. The locked door groups also made the least number of approach responses.

The purpose of this experiment was to examine the role of the approach response in a secondary reinforcement $\left(S^{r}\right)$ paradigm with children. The notion of an approach response has been incorporated into several theoretical descriptions of secondary reinforcement phenomena (e.g., Dinsmoor, 1950; Myers, 1958; Myers \& Myers, 1965). Both discriminative stimulus and discrimination theory hypothesize that the approach response, through training, becomes part of the chain of responses that leads to reinforcement, but not part of the behavior chain occurring on nonreinforced trials. During extinction, presentation of the stimulus associated with reinforcement should elicit the response chain associated with reinforcement. Interference with the approach response should interrupt this chained behavior, creating a difference between training and test conditions, and therefore reduce extinction responding. However, if the stimulus situation associated with nonreinforced trials is presented following training, and the approach response prohibited, extinction responding should be less affected.

In the present study, a specific empirical test has been made of the role of the approach response in the $\mathrm{s}^{\mathbf{r}}$ learning situation. A door was added to the standard primary reinforcement dispensing mechanism (slot tray) and a door-lift or door-touch was defined as an approach response. This permitted both observation of the approach response and interference with it, as the door could be locked from within. In training, all groups received the same $25 \%$ candy reinforcement schedule, with two light stimuli, one presented on candy reinforced trials (positive) and one on nonreinforced trials (negative). In extinction, half the groups received the positive stimulus for each response; the others received the negative stimulus for each response. In addition, for half of each of these groups the slot tray door was locked during extinction.

\section{Method}

The Ss were 32 boys and 32 girls between the ages of 4 years 9 months and 6 years 2 months, attending kindergarten in Northampton, Mass. ${ }^{2}$ In addition, three groups of 16 Ss each, run by these Es for Morningstar's doctoral dissertation (1966) were employed as controls to complete the design. The apparatus and general procedure have been described previously (Myers \& Myers, 1965; Morningstar, 1966). The major change for this study was the addition of a small Plexiglas door with a knob, which covered the slot tray aperture for the four experimental groups. This door could be lifted by sliding it upwards by means of its knob; it could also be locked in place from within the unit.

During the training phase, each $S$ was required to press the button 80 times; 20 of these responses were followed by the positive stimulus (colored light) for $1.5 \mathrm{sec}$ and then by delivery of candy. The other 60 responses were followed by the negative stimulus for $1.5 \mathrm{sec}$ and no candy. The four experimental groups had to lift the door over the slot tray to obtain the candy, and the $E$ recorded the number of times the door was lifted after a negative stimulus presentation. For the three control groups no door was present. One half of the Ss in each group were trained with red as the positive stimulus, and green as the negative stimulus, while the other half were trained with green positive, red negative. All groups and counterbalancing conditions (sex and color of positive stimulus) were distributed equally between two Es.

There were seven extinction groups, four experimental and three control. Two experimental groups and one control group received the positive stimulus for $1.5 \mathrm{sec}$ following each response; two experimental groups and one control group received the negative stimulus for $1.5 \mathrm{sec}$ following each response. For one experimental group in each of these two stimulus conditions the slot tray door was present unlocked; for the other experimental groups the door was locked. For the two control groups the door was absent. The third control group was the no-stimulus control condition in which no stimulus was presented and no door was present.

During the testing phase, $E$ recorded the number of button presses per min until $S$ asked to return to the classroom, or until the end of $16 \mathrm{~min}$, at which time $E$ terminated the session. For the four experimental groups, E also recorded the number of times an approach response (door-lift or door-touch) followed a button press response. Any $S$ who returned to the classroom before $16 \mathrm{~min}$ extinction period was over 
Table 1

Mean Number of Button-Press and Approach Responses in Extinction

\begin{tabular}{|c|c|c|c|c|}
\hline \multirow{2}{*}{$\begin{array}{l}\text { Response: } \\
\text { Extinction Stimulus: }\end{array}$} & \multicolumn{2}{|c|}{ Button-Press } & \multicolumn{2}{|c|}{ Approach } \\
\hline & Positive & Negative & Positive & Negative \\
\hline \multicolumn{5}{|l|}{ Extinction Group } \\
\hline Unlocked Door & 134.3 & 148.6 & 68.9 & 61.6 \\
\hline Locked Door & 59.9 & 141.0 & 4.6 & 19.6 \\
\hline No Door & 154.3 & 262.9 & $\ldots$ & $\ldots$ \\
\hline No Stimulus & \multicolumn{2}{|c|}{109.1} & $\ldots$ & $\ldots$ \\
\hline
\end{tabular}

received a score of zero for the remaining minutes. Throughout the training and testing periods, $S$ was allowed to respond at his own rate.

\section{Results and Discussion}

The mean number of button press and approach responses in extinction for each of the extinction groups may be seen in Table 1 . The greatest number of button press responses was made by the No-Door groups and the least number of responses was made by the Locked Door groups ( $F=7.76, \mathrm{df}=2 / 84, \mathrm{p}<.001)$. The Negative Stimulus groups made more extinction responses than the Positive Stimulus groups $(F=9.03$, $\mathrm{df}=1 / 84, p<.01$ ). The extinction block effect for $4 \mathrm{~min}$ time blocks was significant $(F=16.91, d f=3 / 252, p<$ $.001)$, reflecting the usual response rate decrement during extinction; however, the Locked Door groups showed less of a decrement, responding at approximately the same very low rate in the last three time periods ( $F=2.55, \mathrm{df}=6 / 252, p<.05)$. Dunnett's $t$ statistic was used to compare each of the six extinction groups and the No Stimulus control; all groups made significantly more button press responses than the control, except for the Locked Door-Positive Stimulus group, which made significantly less responses (df $=7 / 84$; all ps $<.05$ ) .

Examination of approach responding during extinction (see Table 1) shows that the Unlocked Door groups made more door-touching responses following button presses than did the Locked Door groups ( $F=13.59$, $\mathrm{df}=1 / 56, \mathrm{p}<.001)$. About the same number of doortouch responses was made by both Positive and Negative Stimulus groups in Unlocked Door conditions. However, when the door was locked, the Positive Stimulus group made fewer door-touch responses than the Negative Stimulus group, although the appropriate $F$ ratio did not attain significance. There was a decrease in door-touch response rate over extinction blocks, corresponding to that for button press responses $(F=180.69$, df $=3 / 168, p<.001)$. A series of product-moment correlations between the number of lifts of the door after the negative stimulus in training and the number of button press and door-touch responses in extinction were conducted, but revealed no systematic relationships.

The results are in general consistent with predictions of the discrimination hypothesis of extinction behavior (Myers \& Myers, 1965) which states that the greatest resistance to extinction will be shown by those groups for which the change from training to extinction conditions is least. On $100 \%$ of extinction responses the Unlocked Door-Negative Stimulus group and the No Door-Negative Stimulus group experienced the same stimulation which they received for $80 \%$ of training responses. For the equivalent Positive Stimulus groups, on $100 \%$ of extinction responses the stimulation was the same as received for only $20 \%$ of training responses. In both instances the Negative Stimulus group made more responses than the Positive Stimulus group. Furthermore, the addition of the doorlift response in training which was not necessarily present in extinction created a difference between training and extinction for all four experimental groups that was not present for the two No Door control groups; all four experimental groups responded less in extinction than the two No Door control groups.

The approach response data are surprising in several ways. Primarily, the number of approach responses is very small relative to the number of button press responses. Even in the Unlocked Door-Positive Stimulus group, approach responses were made following only about $50 \%$ of the button press responses. Second, approximately the same numbers of approach responses were made following positive and negative stimuli in extinction. Finally, the number of approach responses in extinction was not systematically related to the number of approach responses following the negative stimulus in training.

On the other hand, locking the door of the slot tray unquestionably produced a considerable decrease in both button press and approach responding with the positive stimulus. A negligible decrease in button pressing, and a less extreme drop in approach responding was noted with the negative stimulus. Apparently, the approach response does become part of the chain of responses leading to the positive stimulus and candy, to the extent that interference with the approach response greatly changes the situation and reduces extinction responding. However, a barrier to the approach response does not seriously reduce extinction responding to the negative stimulus, strongly suggesting that it is not an integral part of this response chain.

References

DINSMOOR, J. A. A quantitative comparison of the discriminative and reinforcing functions of a stimulus. J. exp. Psychol, 1950, 40, 458-472.

MORNINGSTAR, M. Cue and reinforcing properties of a stimulus as a function of training conditions. Unpublished doctoral dissertation, University of Massachusetts, 1966.

MYERS, J. L. Secondary reinforcement: A review of recent experimentation. Psychol. Bull., 1958, 55, 284-301.

MYERS, N. A., \& MYERS, J. L. A test of a discrimination hypothesis of secondary reinforcement. J. exp. Psychol, 1965, 70, 98-102. Notes

1. This research was supported by funds from National Institutes of Health Grant HD-00898-07. The authors wish to thank J. L. Myers for his suggestions on the design and comments on the manuscript. 2. The authors wish to thank John Buteau, Superintendent of Schools, and Robert Moriarty, Elementary School Supervisor, Northampton, Massachusetts, for their cooperation in providing facilities and Ss for this study, and Florence Mador for assistance in running Ss. 